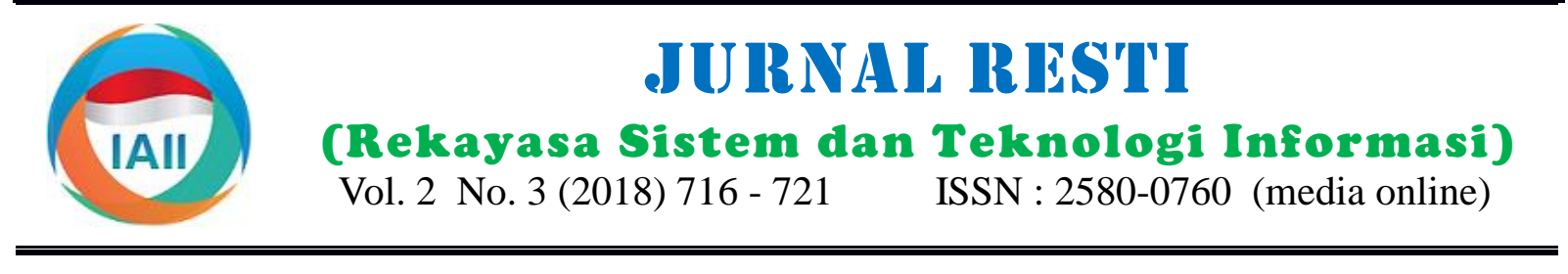

\title{
Aplikasi Penerimaan Mahasiswa Baru Online Dengan Sms Gateway di STMIK Indonesia Padang
}

\author{
Monanda Rio Meta ${ }^{\mathrm{a}}$, Ilham Eka Putra ${ }^{\mathrm{b}}$, Annisa Urfa ${ }^{\mathrm{c}}$ \\ asistem Informasi, STMIK Indonesia Padang, monandario@ stmikindonesia.ac.id \\ bSistem Informasi, STMIK Indonesia Padang, ilhamekaputra@stmikindonesia.ac.id \\ 'Sistem Informasi, STMIK Indonesia Padang, annisaurfaa@ gmail.com
}

\begin{abstract}
STMIK Indonesia Padang is one of the high school level education isntitutions in Padang. In Students admission activities, STMIK Indonesia is still announce the result conventionally, its affect the comfort of prospective students. Examinees have to wait until the reslut announced to know if they could register or not. There for, SMS Gateway system is neededto improve service to prospective students and improve the image of STMIK Indonesia Padang it self in society. This research intented to build a SMS Gateway aplication to help students admission activities at STMIK Indoenesia Padang. This SMS Gateway developed by waterfall method, with PHP programming language and Gamu aplication to integrate the System to SMS Gateway and tested with black box method. The result is a SMS Gateway Information System to inform students passing grade.
\end{abstract}

Keywords: SMS Gateway, Students Admission, Waterfall method, Blackbox method

\begin{abstract}
Abstrak
STMIK Indonesia Padang adalah salah satu lembaga pendidikan tinggat sekolah tinggi di kota Padang. Dalam kegiatan penerimaan mahasiswa baru STMIK Indonesia masih mengumumkan hasil ujian dengan cara konvensional sehingga ini berpengaruh kepada kenyamanan peserta ujian. Peserta harus menunggu sampai hasil diumumkan untuk mengetahui apakah mereka bisa mendaftara ulang atau tidak. Oleh karena itu, diperlukan sebuah sistem layanan berbasis SMS Gateway untuk meningkatkan pelayanan kepada calon mahasiswa dan meningkatkan citra STMIK Indonesia Padang itu sendiri di mata masyarakat umum. Penelitian ini bertujuan untuk membanun sebuah aplikasi SMS Gateway untuk membantu kegiatan Penerimaan Mahasiswa Baru di STMIK Indoenesia Padang. SMS Gateway ini dikembangkan dengan metode waterfall, menggunakan bahasa pemrograman PHP dan aplikasi Gamu untuk mengintegrasikan aplikasi dengan SMS Gateway dan diuji dengan metode black box. Hasilnya adalah sebuah sistem informasi berbasis SMS Gateway untuk menginformasikan kelulusan calon mahasiswa baru.
\end{abstract}

Keywords: SMS Gateway, Penerimaan Mahasiswa Baru, Metode Waterfall, Metode Blackbox

@2018 Jurnal RESTI

\section{Pendahuluan}

STMIK Indonesia Padang adalah salah satu lembaga pendidikan tingkat Sekolah Tinggi yang mempunyai visi untuk menjadi salah satu kampus terkemuka di bidang IT. Salah satu usaha STMIK Indonesia untuk menghasilkan lulusan yang kompeten adalah dengan mengadakan ujian masuk penerimaan mahasiswa baru.

Masalah yang dihadapi STMIK Indonesia dalam kegiatan Penerimaan Mahasiswa Baru adalah saat menggumumkan hasil ujian kepada calon mahasiswa baru. Calon mahasiswa terpaksa menunggu sampai hasil ujian dikalkulasi dan diumumkan di kampus. Hal ini bisa berakibat kepada kenyamanan mahasiswa selama melamar dan kesan tidak baik terhadap kampus. Hal ini disebabkan karena kualitas pelayanan berpengaruh besar terhadap loyalitas konsumen dalam hal ini calon mahasiswa [1]. Sebagai kampus teknologi informatika, sudah sepantasnya bagi STMIK Indonesia untuk memanjakan mahasiswa dan calon mahasiswanya dengan layanan berbasis IT.

Diterima Redaksi : 01-10-2018 | Selesai Revisi : 02-11-2018 | Diterbitkan Online : 16-12-2018 
Perkembangan teknologi telepon genggam atau SmartPhone telah membawa kita kepada gaya hidup baru [2]. Hampir semua kegiatan sehari-hari kini bisa dilakukan dengan ponsel. Berbagai fitur yang dimiliki ponsel saat ini menjadikan ponsel sebaai sarana efektif untuk komunikasi dan penyebaran informasi. Selain Social Media, fitur yang tak kalah sering digunakan pengguna ponsel untuk berkirim pesan adalah $S M S$ (Short Message Service).

Seiring dengan berkembangnya teknologi SMS, SMS gateway menjadi pilihan dalam menyebarkan informasi secara masal. SMS gateway sudah menjadi teknologi yang sangat digemari untuk bidang bisnis karena kemudahan yang diberikan dalam pelayanan terhadap pelanggan [3]. Tidak ketinggalan di dalam dunia pendidikan. SMS gateway sudah dipakai dalam penyebaran informasi nilai siswa di SMA Negeri (Prasetyo Teguh \& Kusrini, 2012). Selain untuk kebutuhan informasi nilai siswa, SMS gateway juga telah dapat meningkatkan pelayanan komunikasi di sekitar akademika Fakultas Ilmu Komputer di Universitas Sri Wijaya sehingga pengiriman pesan lebih realtime dan memudahkan untk didokumentasikan [4].

Dengan segala keunggulan yang dimiliki oleh SMS gateway, sudah seharusnya STMIK Indonesia sebagai kampus yang bergerak di bidang pendidikan Ilmu Manajemen Informatika menerapkan teknologi ini untuk meningkatkan pelayanan terhadap calon mahasiswa dengan mengirimkan hasil ujian secara langsung ke ponsel peserta ujian.

\section{Tinjauan Pustaka}

Penelitian ini memanfaatkan aplikasi Gammu untuk menjalankan aplikasi SMS Gateway dalam mengirimkan pesan kepada calon mahasiswa. SMS Gateway dan Gammu akan dibahas lebih lanjut di bawah ini.

\subsection{SMS Gateway}

SMS Gateway adalah sebuah aplikasi yang bisa mengirimkan pesan singkat tanpa perantara ponsel dan internet. Aplikasi ini mengirimkan pesan melalui modem GSM/GPRS dan SIM card. Aplikasi ini bisa mengirimkan pesan privasi begitu juga pesan broadcast secara masal. Aplikas ini berhubungan langsung dengan mikrokontroler modem dan menggunakan perintah khusus untuk terhubung dengan provider jaringan. SMS gateway juga dapat menampilkan pesan dan melaporkan jumlah pesan tersimpan dan juga pesan terkirim.[5]

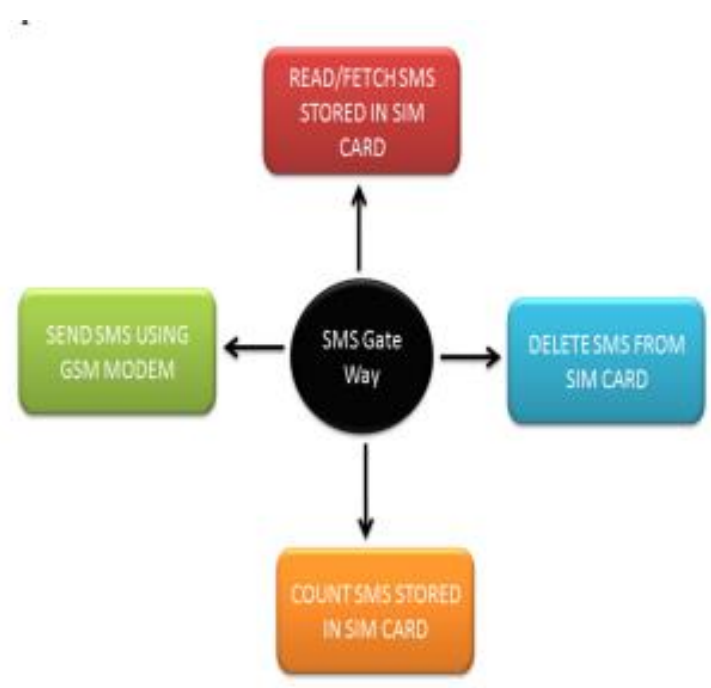

Gambar 1. Konten SMS Gateway

\section{$2.2 \mathrm{Gammu}$}

Gammu (GNU All Mobile Management Utilities) adalah sebuah project untuk membuat perintah, driver, dan software agar dapat menjalankan segala fungsi yang berkaitan dengan telpon selular. Gammu dikembangkan dibawah GNU GPL 2 sehingga meberikan kebebasan dalam menggunakan dan mengembangkannya tanpa khawatir biaya yang mahal. Gammu menggunakan database MySQL untuk menyimpan data pesan. [6]

\section{Metodologi Penelitian}

Aplikasi SMS gateway yang akan dipakai untuk penerimaan mahasiswa baru ini dikembangkan dengan metode SDLC klasik yaitu metode Waterfall karena dinilai cepat dalam hal pengembangan sebuah software aplikasi. Tahap Analisis System, Desain Sistem, Implementasi Sistem, dan Pengujian Sistem.

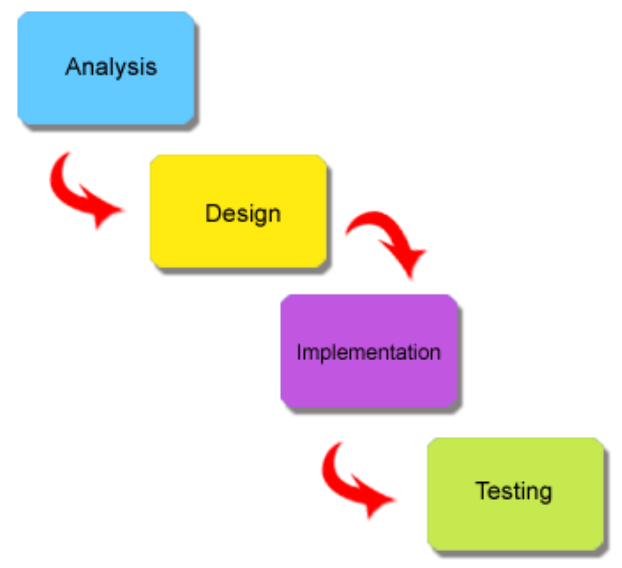

Gambar 2. Waterfall Method 
Tahap analisis dilakukan dengan mengobservasi

Tabel 1 Dokumentasi Naratif Use Case Lihat Data Calon

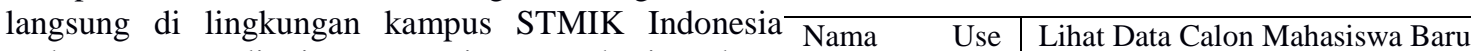
Padang tentang alir sistem penerimaan mahasiswa baru Case di kampus, kemudian menganalisa masalah-masalah Aktor yang mungkin terjadi dalam prosesnya. Sedangkan di Deskripsi tahap Desain Sistem, sistem digambarkan denan tools perancangan sistem berupa Activity Diagram, selanjutnya pada tahapan implementasi sistem, sistem dibuat dengan menggunakan bahasa pemograman php dan database menggunakan mysql. Pada tahapan akhir yaitu pengujian sistem dilakukan dengan blackbox Pra-kondisi testing. Pengujian dengan blackbox testing ini diharapkan mampu menguji segala interface yang ada pada sistem agar terhindar dari error pada sistem.

\section{Hasil dan Pembahasan}

\subsection{Rancangan Sistem}

\section{a. Use Case Diagram}

Use case digunakan untuk menggambarkan bagaimana seseorang akan menggunakan atau memanfaatkan sistem.

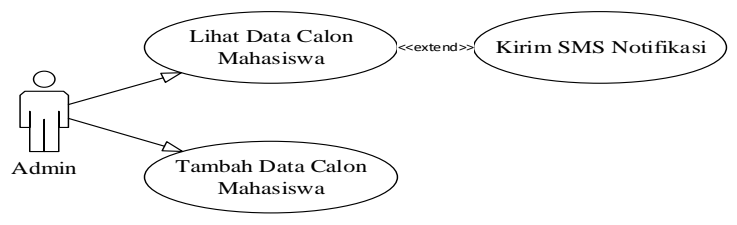

Gambar 3 Use Case Diagram Sistem Informasi Penerimaan Mahasiswa Baru

\section{Bidang Khas}

\section{Admin}

Proses ini menjelaskan bagaimana menampilkan data calon mahasiswa baru berdasarkan data calon mahasiswa yang telah diinputkan pada menu tambah calon mahasiswa baru

Sudah masuk aplikasi

Kegiatan Respon Sistem

Pengguna

Pilih Menu Data Menampilkan data Mahasiswa Baru calon mahasiswa baru

Post-kondisi Data calon mahasiswa baru ditampilkan pada window

2) Nama Use Case : Aktifkan SMS Notifikasi Aktor : Admin

Tujuan : Mengaktifkan SMS Notifikasi Untuk Mengirim SMS Pada Hari H Rapat Dilaksanakan Dan Pada H-1 Sebelum Rapat Dilaksanakan

Tabel 2 Dokumentasi Naratif Use Case Aktifkan SMS Notifikasi

\begin{tabular}{|c|c|}
\hline Nama Use Case & Kirim SMS Notifikasi \\
\hline Aktor & Admin \\
\hline Deskripsi & $\begin{array}{l}\text { Proses ini menjelaskan bagaimana } \\
\text { mengirim sms notifikasi untuk } \\
\text { mengirimkan SMS ke calon mahasiswa } \\
\text { baru mengenai kelulusan. }\end{array}$ \\
\hline Pra-kondisi & $\begin{array}{l}\text { Sudah masuk ke tampilan antarmuka } \\
\text { sistem }\end{array}$ \\
\hline Bidang Khas & $\begin{array}{l}\text { Kegiatan } \\
\text { Pengguna }\end{array}$ \\
\hline & $\begin{array}{l}\text { Mengirim SMS } \\
\text { berdasarkan data no } \\
\text { hp calon mahasiswa } \\
\text { dan } \\
\text { mahasiswa apakah } \\
\text { lulus atau tidak } \\
\text { lulus }\end{array}$ \\
\hline
\end{tabular}

SMS sementara tersimpan di kotak keluar dan jika terkirim akan tersimpan ke pesan terkirim, kotak keluar terhapus otomatis dan SMS terkirim ke calon mahasiswa yang lulus atau tidak lulus.

1) Nama Use Case : Lihat Data Calon Mahasiswa Baru

Aktor : Admin

Tujuan

: Menampilkan data calon mahasiswa baru

3) Nama Use Case : Tambah Data Calon Mahasiswa Baru
Aktor
: Admin
Tujuan : Menginputkan data calon mahasiswa baru 
Tabel 3 Dokumentasi Naratif Use Case Tambah Data Calon Mahasiswa Baru

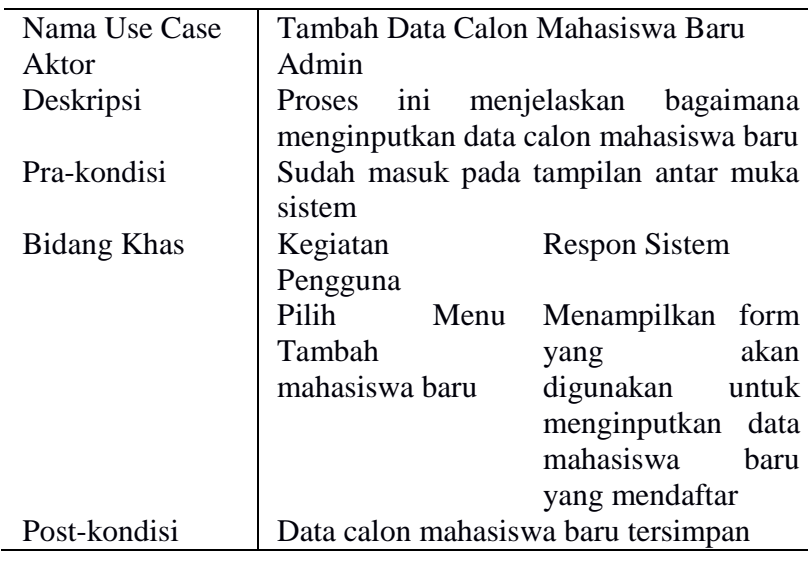

\section{b. Activity Diagram}

Perancangan sistem menggunakan activity diagram dimana activity diagram menggambarkan aliran kerja Desain sistem informasi yang diimplementasikan dari sebuah sistem, atau menu yang ada pada sistem. dalam bahasa pemograman php menghasilkan sebuah Diagram aktivitas menggambarkan aktivitas sistem sistem informasi penerimaan mahasiswa baru. Gambar bukan apa yang dilakukan aktor.

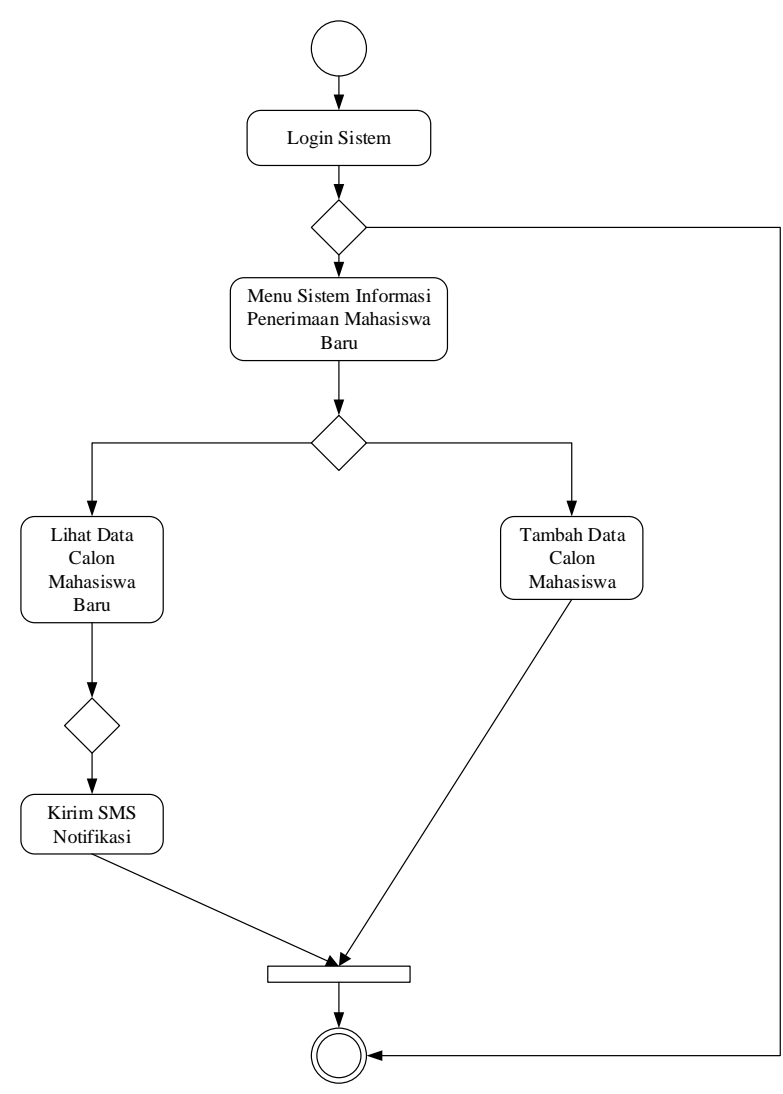

Gambar 4 Activity Diagram Sistem Informasi Penerimaan Mahasiswa Baru
Dari gambar 4, diambarkan sistem berjalan dimulai ketika user login, ketika user login maka sistem menampilkan menu-menu yang ada pada sistem tersebut. lalu user dapat memilih menu lihat data calon mahasiswa baru dan tambah data calon mahasiswa baru.

Pada menu lihat data calon mahasiswa, user dapat melihat data calon mahasiswa yang terlah diinputkan, pada menu tersebut terdapat button untuk mengirimkan $\mathrm{m}$ sms notifikasi hasil penerimaan mahasiswa baru, button n tersebut berfungsi untuk mengirimkan sms kepada calon mahasiswa yang lulus ataupun tidak lulus dalam penerimaan mahasiswa baru di STMIK Indonesia. Pada menu tambah data calon mahasiswa, user dapat memasukkan data mahasiswa dan no pendaftaran serta nilai calon mahasiswa tersebut dan akan tersimpan ke dalam database.

\subsection{Implementasi}

5 menampilkan halaman login dimana user akan menginputkan username dan password untuk dapat masuk ke dalam sistem.

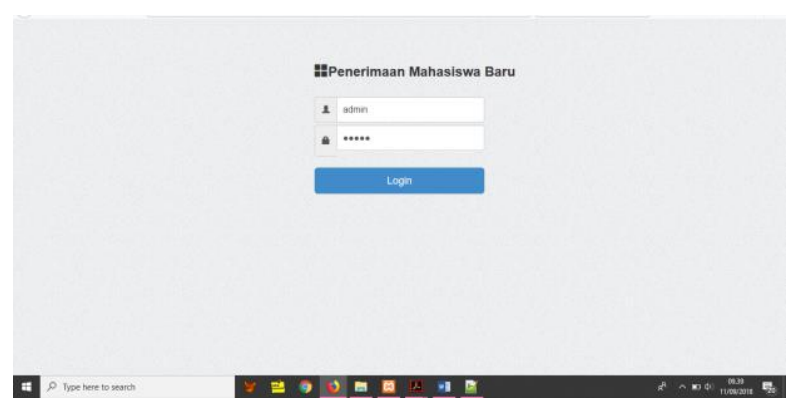

Gambar 5. Tampilan Login

Tampilan awal setelah user login ke sistem dengan menginputkan username dan password dapat dilihat pada gambar 6, user dapat memilih menu yang telah disediakan oleh sistem.

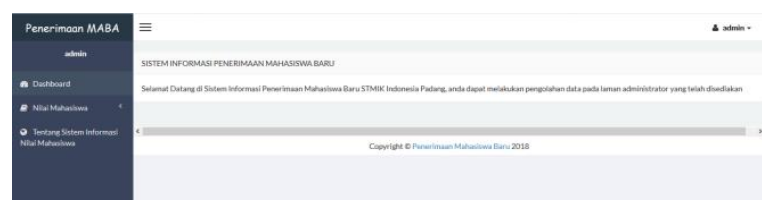

Gambar 6 Tampilan Halaman Utama Sistem

Gambar 7 merupakan halaman untuk menambahkan data calon mahasiswa dan memproses nilai calon mahasiswa untuk menentukan calon mahasiswa 
tersebut lulus atau tidak lulus. User menginputkan Gambar 10 merupakan tampilan hasil implementasi nama, no pendaftaran, no hp mahasiswa dan nilai yang jika sms notifikasi berhasil dikirimkan.

diperoleh calon mahasiswa dan mengklik button proses untuk memperoleh keterangan lulus atau tidaknya calon mahasiswa tersebut.
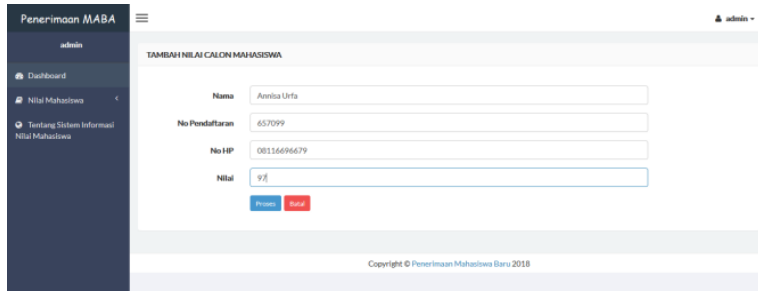

Gambar 7 Tampilan Tambah Nilai Calon Mahasiswa

Gambar 8 merupakan tampilan setelah dilakukannya pemprosesan nilai calon mahasiswa, sistem akan menampilkan keterangan dari seorang calon seorang mahasiswa apakah calon mahasiswa tersebut lulus atau tidak lulus dalam penerimaan mahasiswa baru. Setelah itu user dapat melakukan penyimpanan data calon mahasiswa tersebut dengan mengklik button simpan pada halaman yang telah tersedia.
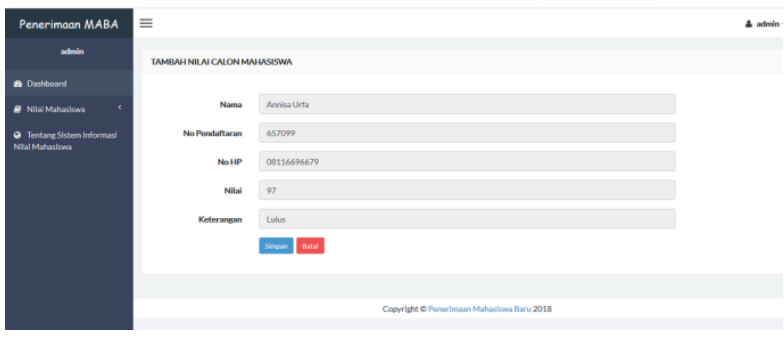

Gambar 8. Tampilan Proses Nilai Calon Mahasiswa

Gambar 9 berikut ini merupakan tampilan data calon mahasiswa yang telah diinputkan sebelumnya, data calon mahasiswa menampilkan nama, No Pendaftaran, No Hp, Nilai dan Keterangan. Pada tampilan data calon mahasiswa ini user dapat melakukan pengiriman sms notifikasi kepada masing-masing calon mahasiswa untuk mengumumkan lulus atau tidak lulusnya seorang mahasiswa dengan mengkilk button kirim sms notifikasi.
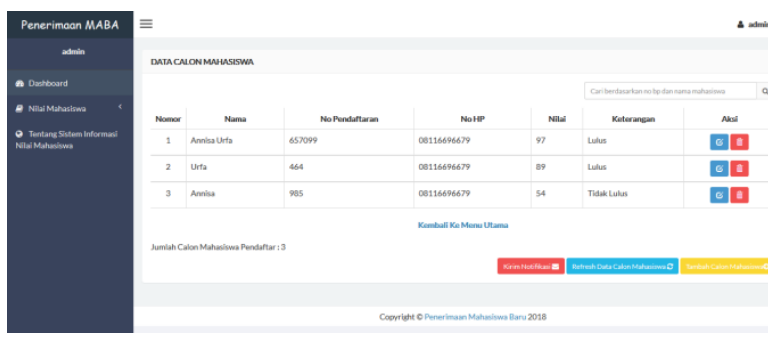

Gambar 9. Tampilan Data Calon Mahasiswa

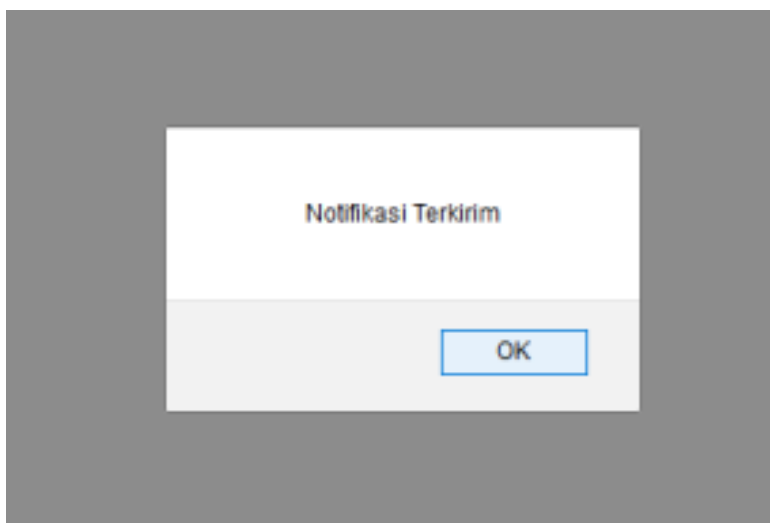

Gambar 10. Tampilan Notifikasi SMS Terkirim

Gambar 11 merupakan tampilan isi pesan yang diterima di handphone penerima sms notifikasi, pesan yang diterima berisikan informasi mengenai mahasiswa yang lulus atau tidak lulus pada penerimaan mahasiswa baru STMIK Indonesia Padang.

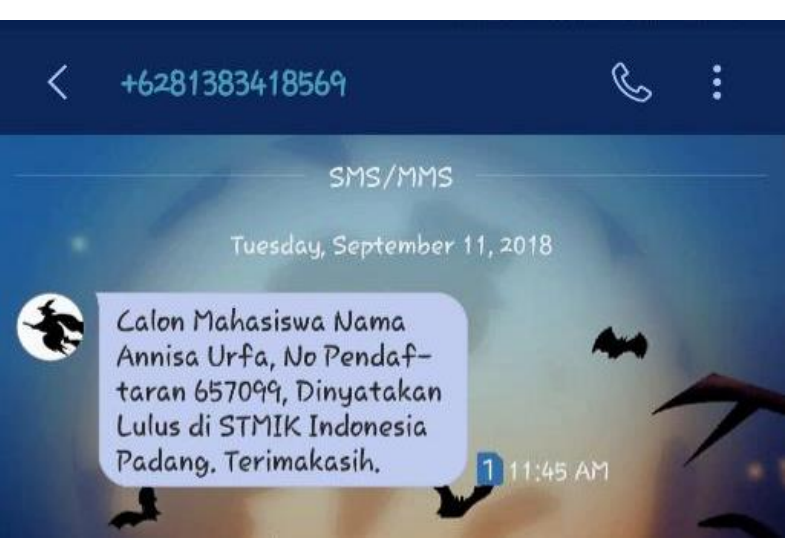

Gambar 11. Tampilan SMS di Handphone Penerima

\subsection{Pembahasan}

Aplikasi penerimaan mahasiswa online di STMIK Indonesia Padang menggunakan bahasa pemrograman PHP dan database MySQL telah berhasil dibuat. Hasil ini selaras dengan penelitian Aryani yang menyatakan bahwa gammu dapat diterapkan di beberapa bahasa pemrograman termasuk PHP (Aryani diah, et.all : 2015). Dalam kasus STMIK Indonesia ini penerapan SMS gateway masih terbatas kepada komunikasi satu arah. Peserta ujian hanya menerima sms ketika panitia mengirimkan pengumuman hasil ujian. Fitur yang ditawarkan SMS gateway tidak hanya sekedar mengirim SMS namun juga bisa membaca request dari

Jurnal RESTI (Rekayasa Sistem dan Teknologi Informasi) Vol . 2 No. 3 (2018) 716 - 721 
SMS yang masuk [7] sehingga aplikasi atau sistem mendanai penelitian ini denan nomor SK informasi penerimaan mahasiswa baru ini masih bisa 020/K.A/LPPM/STMIK-I/2018. Seterusnya penulis dikembangkan menjadi sistem yang lebih besar seperti berterimakasih kepada dosen-dosen dan mahasiswa sistem informasi Akademik yang dapat mempermudah yang telah banyak membantu merampungkan informasi di dalam lingkungan kampus [8]. Sistem tulisan ini.

berbasis SMS gateway ini berikutnya dapat pula dikembangkan untuk distribusi informasi untuk berbagai tingkat level manajemen.

\section{Kesimpulan}

Dari uraian di atas penulis bisa mengambil beberapa kesimpulan yang akan dibahas satu persatu di bawah ini.

\subsection{Simpulan}

Sistem Penerimaan Mahasiswa Baru Berbasis SMS Gateway di STMIK Indonesia Padang telah berhasil dikembangkan menggunakan bahasa pemograman PHP, database mysql dan memanfaatkan layanan SMS gateway dengan menggunakan gammu sebagai perantara. Proses pengembangan berdasarkan model Waterfall yang meliputi empat tahap yaitu (1) Analisis kebutuhan, (2) Desain, (3)Implementasi (4) Pengujian. Sistem Informasi Penerimaan Mahasiswa Baru telah sesuai dengan kebutuhan yang diharapkan berdasarkan perancangan yang telah dilakukan sebelumnya.

\subsection{Saran}

Sistem Informasi berbasis SMS gateway ini masih bisa dikembangkan lagi untuk kebutuhan yang lebih luas di lingkungan kampus. Pengembangan tidak hanya terbatas dengan bahasa pemrograman PHP saja akan tetapi juga bisa menggunakan bahasa pemrograman lain karena fleksibilitas yang dimiliki oleh aplikasi gammu sebagai software perantara.

\section{Ucapan Terima Kasih}

Penulis mengucapkan terimakasih kepada pihak STMIK Indonesia Padang yang telah bersedia

\section{Daftar Rujukan}

[1] Sofyan, Indra Lutfi., et.all, 2013. Pengaruh Fasilitas dan Kualitas Pelayanan Terhadap Loyalitas, Melalui Kepuasan Konsumen Sebagai Variabel Intervening pada Star Clean Car Wash Semarang. DIPONEGORO JOURNAL OF SOCIAL AND POLITIC, Vol. 10, pp. 1-12.

[2] Maulidar, Sri., 2017. PengaruhPenggunaan Smartphone Dalam Gaya Hidup Modern Terhadap Komunikasi Interpersonal Kalangan Pemuda di Kecamatan Syiah Kuala, Banda Aceh, JurnalImiah Mahasiswa FISIP Unsyiah, Vol. 2, No. 4, pp. 2434, November 2017.

[3] Dyantina, Ovi., et.all. 2012. Penerapan Customer Relationship Management (CRM) Berbasis Web (Studi Kasus Pada Sistem Informasi Pemasaran di Toko YEN-YEN). Jurnal Sistem Informasi (JSI), Vol. 4, No.2, pp. 516-529, October 2012.

[4] Afrina, Mira., Ibrahim, Ali. Pengembangan Sistem Informasi SMS Gateway Dalam Meningkatkan Layanan Komunikasi Sekitar Akademika Fakultas Ilmu Komputer Unsri. Jurnal Sistem Informasi (JSI), vol. 7, no. 2, pp. 852-864, October 2015.

[5] Goel, Utkarsh., et.all., IEEE (The Institute of Electrical and Electronic Engineers), 2011. 3rd International Conference on Communication Software. Xi'an, China, 08 September 2011. United Nations: New York.

[6] Islahuddin, Muhammad Ishaq., Subari, Arkhan. Pemanfaatan Sms Gateway Dengan Gammu Dan Webcam Berbasis Visual Basic 6.0 Pada Sistem Keamanan Rumah. GEMA TEKNOLOGI,Vol.17, No.3, pp.116-123, April-Oktober 2013.

[7] Aryani, Diah., et.all. 2015. Aplikasi Web Pengiriman Dan Penerimaan Sms Dengan Gammu SMS Engine Berbasis PHP. EJurnal Raharja, Vol. 8, No.3, pp. 174-190, Mei 2015.

[8] Wiharto, Yudi. 2011. Aplikasi Web Pengiriman Dan Penerimaan Sms Dengan Gammu SMS Engine Berbasis PHP. E-Jurnal Raharja, Vol. 1, No.1, pp. 1-28, Januari 2011.

[9]Wiyono, Adi Restu, et.all. 2015. Perancangan Sistem Informasi Penerimaan Mahasiswa Baru Berbasis Web di STMIK Tasikmalaya. Jurnal Majalah Ilmiah Unikom, Vol.13, No.2, pp. 179-188, December 2015.

[10]Chandra, Tintin. 2015. Perancangan Sistem Informasi Pendaftaran Mahasiswa Baru Pada Perguruan Tinggi X Berbasis Web. Jurnal Times, Vol.IV,No.2, pp 31-34. 